\title{
EบบCÃ̃o Erealidade \\ 'This is The End, My Beautiful Friend!': lazer sério e o fim da carreira
}

\begin{abstract}
Saulo Neves de Oliveira'
Johannes Doll'

'Universidade Federal do Rio Grande do Sul (UFRGS), Porto Alegre/RS - Brasil

RESUMO - 'This is The End, My Beautiful Friend!'! lazer sério e o fim da carreira. $\mathrm{O}$ número de corredores de rua cresce cada vez mais e entre eles, especialmente o grupo dos com mais idade. Mas tudo que tem um início tem um fim, também a "carreira" de um corredor. Confrontando-se com limitações, muitas vezes causadas pelo envelhecimento, o sujeito precisa lidar com esta situação. O presente artigo interpreta o fim da carreira de um corredor como um momento de aprendizagem frente a um novo desafio. São registrados os diferentes fatores que influenciam neste processo e analisadas as várias formas de lidar com a possível interrupção da atividade no contexto de um grupo de corrida de Porto Alegre.

Palavras-chave: Envelhecimento. Carreira. Lazer Sério. Corredores.
\end{abstract}

ABSTRACT - 'This is The End, My Beautiful Friend!': serious leisure and the end of career. The number of runners is increasing, among them, especially, the older ones. But everything that starts comes to an end, including a runner's career. Confronting limitations often caused by aging, the older runner has to deal with this situation. This paper interprets the end of career of a runner as a learning moment facing a new challenge. Various factors that influence this process were recorded and the different ways of coping with the end of a runner's career were analyzed in the context of a racing group in Porto Alegre.

Keywords: Aging. Career. Serious Leisure. Runners.

Educação \& Realidade, Porto Alegre, v. 42, n. 1, p. 215-236, jan./mar. 2017. 215 http://dx.doi.org/10.1590/2175-623651581 
'This is The End, My Beautiful Friend!'

\section{Introdução}

Nos últimos anos, o número de adeptos das Corridas de Rua no Brasil tem aumentado surpreendentemente (Sarkis, 2009). Esse crescimento tem ocorrido de forma mais acentuada nas faixas etárias de maior idade, acompanhando o fenômeno do envelhecimento no Brasil. Com isso, essa prática não só ampliou-se, mas também se diferenciou, abrangendo hoje um amplo leque de grupos de corredores com perspectivas e valores bem diferentes. Stigger (2009) chama a atenção para a articulação que há entre o lazer, a cultura e a educação, levando à reflexão sobre a importância de considerar o lazer como uma dimensão que não está separada de outros "[...] processos educativos que fazem parte da vida cotidiana”. Dessa forma, a prática de um esporte, como a corrida de rua, está inserida nas práticas culturais, oferecendo um espaço de vivência significativa ao mesmo tempo em que exige do participante uma série de aprendizagens. Além da aquisição de conhecimentos novos sobre a própria prática do esporte, a inserção no universo de corredores exige do novato aprendizagens culturais, como formas de comunicação, de relacionamento e de lidar com desafios próprios da atividade. Esse processo pode ser visto como uma socialização do novo participante para se tornar membro de um mundo social específico, com comportamentos, valores e etos próprios, o mundo dos corredores (Stebbins, 2008). O processo de entrada neste mundo social, o desenvolvimento das competências e habilidades, a manutenção da permanência e a saída deste mundo são interpretados por Stebbins (2008) como uma carreira.

Neste contexto, o presente artigo busca analisar mais especificamente a parte final das carreiras de corredores de longa distância. Vinculado ao processo de envelhecimento, existe um momento na carreira, em que a performance na corrida, apesar de treinamento e otimização das condições, não avança mais e em que se nota um certo declínio nos resultados. Nessa situação, coloca-se a pergunta, como os corredores lidam com essa situação. Quais são os processos de desenvolvimento empenhados? Os corredores abandonam o esporte e, com isso, o mundo social ao qual pertenciam e que fazia parte da identidade deles? Ou encontram outras formas para se manter no mundo social aceitando a diminuição da performance? E quais são os discursos desenvolvidos para lidar com esta situação?

Os processos de desenvolvimento aos quais nos referimos e buscamos identificar estão relacionados a mecanismos amplamente discutidos no campo da Gerontologia. Esses mesmos são, em geral, ligados a conceitos de envelhecimento. Entre eles, o envelhecimento bem-sucedi$d o$. Ao longo da vida, perdas e ganhos estão presentes e o que se altera é a relação de equilíbrio entre eles, particularmente nos últimos anos da existência. Assim, torna-se importante "[...] iniciar processos adaptativos a fim de maximizar a probabilidade de obter novos ganhos e minimizar a experiência de perdas, mantendo assim as condições que o indivíduo considera como satisfatórias e evitando efeitos prejudiciais da perda quando essa é inevitável” (Villar, 2012, p. 1091, tradução nossa).

216 Educação \& Realidade, Porto Alegre, v. 42, n. 1, p. 215-236, jan./mar. 2017. 
Talvez, um dos modelos mais influentes dentro das teorias que consideram o envelhecimento como um amplo processo de desenvolvimento ao longo da vida, ou teorias de life-span, seja o conhecido como de seleção, otimização e compensação, ou modelo SOC. Esse modelo, proposto por Baltes e Baltes (1990), concebe o envelhecimento bem-sucedido como a combinação e aplicação coordenada de três processos que capacitam o indivíduo a utilizar total e efetivamente seus recursos de desenvolvimento. Esses três processos são (1) seleção, referente ao concentrar-se em objetivos e percursos de desenvolvimento, deixando outros de lado; (2) otimização, ou empenho em adquirir ou incrementar os recursos requeridos para alcançar altos níveis funcionais; e (3) compensação, ou esforços em manter um nível funcional quando recursos disponíveis anteriormente se perdem.

Essa é a perspectiva que utilizamos ao longo do artigo para responder de que forma os corredores lidam com a fase final da carreira. Primeiramente, apresentamos como a pesquisa foi desenvolvida para em seguida expor o mundo dos corredores de rua em geral e, em um segundo momento, um grupo específico de corredores. Posteriormente, passamos à principal lente teórica que utilizamos em nossas análises e nossos achados.

\section{Metodologia}

Nossa aproximação à carreira dos corredores de longa distância se deu qualitativamente, em um estudo exploratório. Assim, recorremos inicialmente a observações diretas de um grupo de corredores entre os anos de 2008 e 2015. Essas observações foram feitas a partir da participação ativa dos dois autores como corredores do grupo. Antes de tudo, obtivemos o consentimento esclarecido dos participantes da investigação, bem como dos responsáveis pelo grupo. Todas as observações foram registradas em um caderno de campo, como notas que continham as atividades observadas, comportamentos e ações dos corredores. A observação direta, especialmente com a participação do pesquisador, é considerada por diferentes autores uma estratégia imprescindível para um melhor entendimento de um contexto social (Becker, 1952; Patton, 2002) durante as sessões de treinamento, competições e encontros socais, bem como durante momentos de convivência em diferentes espaços. Isso permitiu um enriquecimento do conhecimento sobre o meio social estudado (Adler; Adler, 1994; Stebbins, 2001). Além disso, foram realizadas entrevistas semiestruturadas, visando manter o nível de consistência na formulação das perguntas e oferecer certa flexibilidade aos corredores ao permitir que respondessem às suas próprias maneiras. A carreira e o envelhecimento encontram-se em um campo em que ainda há pouquíssimos estudos (Oliveira; Doll, 2014; Stebbins, 2016) e para o qual as entrevistas semiestruturadas tornam-se uma aproximação importante, já que se trata da exploração de um fenômeno pouco conhecido (Creswell; Plano Clark, 2011).

Os corredores entrevistados foram selecionados a partir de três critérios fundamentais: 1) participação no grupo; 2) idade igual ou su-

Educação \& Realidade, Porto Alegre, v. 42, n. 1, p. 215-236, jan./mar. 2017. 
'This is The End, My Beautiful Friend!'

perior a 45 anos; 2) participação em corridas de longa distância. Foram entrevistados 17 corredores, com idades entre 45 e 68 anos, tendo como objetivo principal compreender suas experiências na modalidade esportiva. Basicamente, os tópicos abordados envolviam características de suas trajetórias como corredores, os porquês de estarem correndo, as relações entre as práticas envolvidas na corrida e sua vida cotidiana, e, finalmente suas percepções sobre o envelhecimento em geral e seu próprio envelhecimento.

O número de entrevistados foi determinado pelo critério de saturação (Glaser; Strauss, 1967), ou seja, quando as informações dadas pelos entrevistados não acrescentam mais qualquer conteúdo e tornamse repetitivas, sem que contribuam para o melhor entendimento do que se quer saber. Logo após, as entrevistas foram transcritas e passaram por um processo de codificação no qual pequenos trechos eram organizados e rotulados com resumidas descrições. As informações contidas nas entrevistas e observações diretas foram cruzadas em um processo de "triangulação" (Patton, 2002, p. 306), que envolve olhar para as duas aproximações e utilizá-las de forma complementar. Em síntese, foram realizadas seis etapas na produção de dados para a investigação: (a) a familiarização com os dados, observando quais os assuntos destacados pelos corredores; (b) a geração e códigos, rotulando os trechos de acordo com as ações identificadas; (c) a identificação de temas relevantes, olhando de forma mais geral e para aspectos relacionados ao envelhecimento; (d) a revisão de temas, buscando avaliar a consistência dos mesmos; (e) a definição do nome adequado para cada tema; e, por fim, (f) a escrita do estudo.

O grupo de corrida de rua em questão é considerado um dos maiores do Estado (RS), tendo sido criado no ano 2005. Uma das características que nos levaram a estudá-lo foi, além do grande número de participantes, a alta heterogeneidade representada pela variedade em termos de gênero, intenções, performances, idades, comprometimento e assim por diante.

\section{Contextualização das Corridas de Rua}

Olhando de forma mais ampla para o contexto social em que o grupo analisado está inserido, o das corridas de rua, conseguimos identificar duas mudanças importantes na última década: alteração no perfil dos participantes das corridas de rua e na característica das próprias provas de corrida.

Entendemos que é no início dos anos 2000 que esses três processos começam a tomar forma no Brasil e, especialmente, na cidade de Porto Alegre. Em nossa análise, o primeiro processo social que ocorre dentro do contexto das corridas de rua é uma alteração no perfil do participante, havendo uma transição de um perfil anterior predominante e particular para uma ampliação do leque participativo (gênero, idade, classe social, performance etc.). Uma marca interessante nesse processo se refere ao aumento na participação de pessoas com idades nas fai- 
xas de 40 a 60 anos. Salgado e Chacon-Mikahil (2006), por exemplo, analisam o número de provas e participantes das corridas de rua realizadas entre os anos 1997 e 2005 em São Paulo. No estudo, dados indicam que $70 \%$ dos participantes das corridas de rua da cidade estão na faixa de pessoas com mais de 40 anos. No mesmo estudo, menos de $1 \%$ dos participantes é considerado corredor de elite.

No Rio Grande do Sul, nossa própria análise sobre as idades dos participantes das corridas de rua em Porto Alegre, em pesquisa feita em $2010^{2}$, indicava o mesmo sentido de mudanças no perfil dos corredores na cidade. Em Porto Alegre, a participação de homens e mulheres com idades superiores a 40 anos nas corridas representa em média $54,78 \%$ e $51,45 \%$, respectivamente. A categoria "G" (faixa etária de 45 a 49 anos) foi a que apresentou o maior crescimento percentual nas participações totais masculinas - de 11,43\% em 2005 passou para 16\% em 2009. Outra categoria masculina que sofreu uma grande alteração foi a categoria " $\mathrm{A}$ " (de 16 a 19 anos), que de 2,86\%, em 2005, aumentou para 4,38\%, em 2007, e decaiu para 0,86\%, em 2009.

Embora não tenhamos dados diretos sobre a renda dos corredores participantes, outros fatores indiretos, como o aumento do valor das taxas de inscrição das provas, nos indicam a mudança neste quesito. Além disso, nossas observações atuais nos mostraram que parte dos corredores que estava praticamente sempre nas provas, entre eles, figuras folclóricas nas corridas em Porto Alegre, desapareceu. Quando conseguimos encontrar uma ou outra dessas personalidades de destaque, a razão para a ausência, indicada queixosamente por algumas, era o alto custo para participação.

Essas mudanças no perfil dos corredores participantes das corridas de rua se relacionam diretamente com um segundo processo identificado nesta modalidade. A dinâmica entre esses processos garante aos eventos de corrida de rua uma forte visibilidade e um grande poder de atração, na medida em que torna o sonho de ser atleta possível para pessoas que antes estavam no anonimato. Diferentes do modelo tradicional bastante comum na cidade, começam a aparecer no mundo social das corridas de rua características inovadoras, no sentido de adotar estratégias para contemplar demandas sociais contemporâneas relacionadas com a participação diferenciada nos eventos e interesses de mercado.

Em meados da década de 2000 até seu final, ainda parecia possível distinguir com certa precisão o que um dos treinadores entrevistados classificava de corridas fashion e corridas convencionais em relação aos tipos de competições que o grupo participava. As corridas convencionais seguiam o que chamamos de modelos tradicionais de corrida $\mathrm{e}$ se baseavam, principalmente, em características como individualidade e competitividade. Nesses modelos, a corrida estava voltada à performance e, assim, a atenção estava sobre os atletas - principalmente vinculados a clubes e entidades de atletismo.

As corridas dos modelos tradicionais são mais populares. Em geral, a maior parte dos corredores pertence às classes sociais mais bai- 
'This is The End, My Beautiful Friend!'

xas e há uma maior participação de corredores de nível de performance mais alto. Para os corredores do estudo, essas corridas tradicionais são para os corredores de verdade, corredores da elite ou para os profissionais. Já os novos modelos de corrida, representados pelas corridas fashion e de ocorrência bastante frequente se baseiam em características relacionadas à coletividade, participação, interatividade e relacionamento social. Esses aspectos não são exclusivos desses modelos, embora se apresentem de forma menos evidente no primeiro. Nas corridas derivadas dos novos modelos, a atenção parece diluída entre os participantes, sujeitos com variados vínculos, atitudes, intensões e, dependendo da especificidade do evento, a disputa pode parecer mais um encontro ou desfile do que uma prova em termos competitivos tradicionais.

Num movimento dialógico entre as configurações dos eventos e os perfis dos participantes, ocorrem mudanças bastante importantes no âmbito das corridas em Porto Alegre nas últimas décadas e surgem nesse contexto os grupos de corrida. Eles reúnem características diferentes das encontradas nas tradicionais equipes de corrida. Essa nova organização dos participantes em grupos de corrida também gerou espaços diferenciados para atletas e ex-atletas, tanto de Porto Alegre quanto de outras cidades do interior do estado do Rio Grande do Sul. Muitos atletas que participavam das corridas de rua passaram a ser convidados por lideranças de dentro dos grupos para serem seus treinadores ou assessores. Alguns deixaram de competir, outros ainda mantiveram de forma menos rigorosa o treinamento e passaram a encarar disputas com menos frequência. Além disso, muitos atletas e ex-atletas formaram seus próprios grupos.

\section{O Grupo Analisado}

É nesse processo histórico que se insere a formação e estabelecimento do grupo de corrida que investigamos. O grupo iniciou suas atividades em 2005, dentro de um clube de esporte e lazer que mantém, dentre outras modalidades esportivas, uma equipe de atletismo desde 1918. A referência esportiva internacional, com o preparo de atletas de nível olímpico no atletismo e a presença em competições de diferentes níveis, por exemplo, marca o espaço em que nasceu o grupo de corrida que analisamos. A proposta inicial do grupo era de oferecer uma alternativa aos sócios do clube para que pudessem praticar a corrida com a supervisão e orientação dos mesmos profissionais que atuavam como treinadores da equipe de atletismo, mais particularmente nas provas de corridas de longa e média distância.

Em relação aos membros, é importante ressaltar que, dentro dos três espaços que nos propomos a analisar o grupo (treinos, competições e confraternizações), participavam tanto os corredores sócios do grupo de corrida quanto os corredores da equipe do clube. Em outras palavras, embora houvesse uma diferença de vínculo institucional entre os corredores, todos participavam juntos - o mesmo uniforme, rotinas similares etc. - e isso acabava por tornar invisíveis essas dife- 
renças no grupo a um observador leigo. Em pontos específicos, havia diferenciação, especialmente quanto à cobrança de resultados direcionada aos corredores da equipe e a realização de treinos em intensidades diferentes. Outro ponto que merece destaque é a heterogeneidade que os corredores sócios do grupo apresentavam diante da homogeneidade, pelo menos expressa, dos corredores da equipe - dentre os corredores sócios, se ouvia, por exemplo, eu vim aqui me divertir um pouco, hoje eu vou fazer meu melhor, compondo uma variedade de atitudes, diferente da textura predominante na composição das falas dos corredores da equipe, como eu estou meio nervoso e eu estou confiante que vou baixar o tempo hoje - relacionado ao resultado que esperavam obter ao final da prova ou treino. Em 2014, o grupo contava com aproximadamente 130 corredores, sendo pouco mais da metade (52\%) de homens e pouco menos (48\%) de mulheres. A faixa etária predominante no grupo estava entre 38 e 54 anos (78\%).

\section{A Primeira Aproximação: qualidades do lazer sério}

Nossas análises foram construídas a partir de nosso olhar como corredores integrantes no grupo que estudamos. Um de nós fazia parte da equipe de atletismo do clube antes e depois da criação do grupo e outro, embora corresse há mais tempo, começou a participar do grupo de corrida em seus primeiros meses de criação. Assim, nossas análises passaram por discussões que só foram possíveis porque possuíamos observações de pontos de vista diferentes. Uma das características que nos chamaram a atenção desde o início era a valorização do compromisso com a realização das atividades em torno da corrida, tanto por parte dos corredores da equipe quanto por parte dos corredores associados. Encontramos na proposta de "lazer sério" (Stebbins, 2008) uma aproximação teórica bastante adequada para esse fenômeno. Para Stebbins (2008, p. 5), o "lazer sério" é

[...] a prática sistemática de uma atividade central por
amadores, praticantes de hobby ou voluntários, conside-
rada substancial, interessante e realizadora e que, em ca-
sos típicos, lança-lhes numa carreira (de lazer) centrada
na aquisição e expressão de uma combinação de habilida-
des, conhecimento e experiência específicos (modificado
de Stebbins, 1992, p. 3, apud Stebbins 2008, p. 5, tradução
autoral).

Em nossos primeiros estudos, buscamos associar nossos dados com o que Stebbins (2008, p. 11-13) chamou de "qualidades distintivas do lazer sério" - a perseverança, o esforço substancial, a carreira, os benefícios duráveis, o mundo social específico e a identificação. Essas qualidades nos indicavam seis dimensões importantes do lazer dos corredores e nos ajudaram a explicar as práticas que observamos.

Percebemos o quanto as qualidades formuladas se aproximavam de nossas observações. Segundo Stebbins (2008), a perseverança é vista como uma necessidade ocasional que surge e se apresenta aos prati- 
'This is The End, My Beautiful Friend!'

cantes do "lazer sério" em casos em que enfrentam situações adversas decorrentes de suas práticas. Assim, a perseverança se tornava evidente quando corredores enfrentavam situações temporariamente limitantes em que precisavam parar de correr por alguma lesão. Por isso, precisavam fazer um treino adaptado que promovesse a recuperação rápida para que pudessem logo voltar às atividades. Essa urgência, muitas vezes, se dava por conta do tempo de treinamento necessário para que atingissem as marcas (tempos ou resultados) que desejavam.

A perseverança necessária aos praticantes do lazer sério é, segundo Stebbins (2008, p. 11), o motor que impulsiona sua segunda qualidade distintiva: a carreira. Como será tratada a seguir, a carreira é um aspecto altamente significativo e estruturador das relações entre os corredores integrantes do grupo de corrida. A carreira está ligada à continuidade na atividade, tanto em períodos de aumento de prestígio e benefícios quanto na diminuição destes.

O esforço substancial representa o empenho dos praticantes do lazer sério na direção de desenvolverem seu conhecimento, treino, experiência ou habilidades. Em nossas análises, compreendia o conjunto de ações que os corredores praticavam em torno do próprio desenvolvimento na corrida. Entretanto, no grupo em que observamos, é um esforço particular, o esforço nas pistas, tanto nas competições quanto nos treinamentos - buscando correr a prova com o máximo empenho ou realizar o treino certinho, dentro do solicitado pelo treinador - o que parece melhor representar essa qualidade para os corredores.

A presença de benefícios duráveis, que reúnem ganhos de ordem emocional e social, foram identificados em maior parte entre os amadores, constitui outra qualidade distintiva do lazer sério. "Os benefícios duráveis desse tipo de lazer surgem da recusa por permanecer um mero praticante, calouro ou novato" (Stebbins, 1982, p. 258, tradução e grifo autorais). Nessa quarta qualidade, encontram-se benefícios como o reconhecimento e a integração social, a melhoria da autoimagem, entre outros. Essas vantagens apareciam nas falas dos corredores, mostrando esses aspectos psicológicos e sociais em realizações coletivas do grupo de corredores.

O mundo social específico se desenvolve em torno do lazer sério. Essa qualidade é evidente na comunidade de praticantes de lazer sério em seu "[...] compartilhar de atitudes, práticas, valores, crenças, objetivos e assim por diante" (Stebbins, 2008, p. 12, tradução autoral). Stebbins (2008) baseia sua proposta de "mundo social” nas concepções desenvolvidas por Unruh (1979; 1980), para quem:

\footnotetext{
A noção de mundos sociais é utilizada para referir uma forma de organização social que não pode ser precisamente demarcada por fronteiras espaciais, territoriais, formais, ou de membresia. Antes, as fronteiras dos mundos sociais devem ser determinadas pela interação e comunicação que transcendem e atravessam os mais formais e tradicionais delineadores de organização (Unruh, 1980, p. 271, tradução autoral).
} 
De acordo com Unruh (1980, p. 277, tradução autoral), o mundo social "[...] deve ser visto como uma constelação reconhecível de atores, organizações, eventos e práticas que se aderem à esfera de interesse e envolvimento dos participantes". Em nosso estudo, ficou evidente a construção de um mundo social específico, estruturado fortemente pela performance, embora essa estrutura apresentasse configurações peculiares nas experiências dos corredores do grupo. Além disso, esse universo estava marcado pela presença de elementos relacionados à linguagem dos corredores, servindo de estratégias para lidarem com diferentes desafios na busca de darem sentido às suas práticas. A forma que os corredores se comunicavam, verbal ou não verbalmente, a utilização de um vocabulário especializado (voltado a questões mais técnicas da corrida, como rodagem, tiros, trote) e cotidiano dos corredores (correr na pipoca, endurecer), além de uma atitude predominantemente de deboche nas conversas entre si.

De acordo com Stebbins (2008), é ao compartilharem desse mundo social que os participantes do "lazer sério" tendem a assemelharse- fortemente uns com os outros, caracterizando a última qualidade distintiva do lazer sério: a identificação (Stebbins, 2008, p. 12-13). Essa qualidade emerge das outras cinco a partir das realizações no lazer sério, que podem ter um apelo identificador maior que o papel profissional de uma pessoa. Essa qualidade de identificação no lazer sério se tornou evidente a nós ao observarmos no grupo de corredores as formas como se vinculavam uns aos outros a partir de elementos que eram comuns a maior parte do grupo. Um deles, segundo nossas análises, que pode ser apontado como a base das atividades em torno das corridas de rua, é a carreira.

\section{A Segunda Aproximação: carreira no lazer}

Em uma segunda aproximação, tivemos como foco as trajetórias dos corredores, dentro das práticas relacionadas à corrida de rua. Essas trajetórias estavam bem ligadas com a proposta de carreira, uma das qualidades distintivas do lazer sério, mencionadas anteriormente.

Stebbins (2008, p. 112) baseia a concepção de "carreira do lazer sério" sobre a "carreira moral" de Goffman (1974) e assim a define como "[...] qualquer trajetória percorrida por uma pessoa durante sua vida" (Goffman, 1974, p. 111). No estudo de Goffman (1974) sobre o comportamento de pacientes em um sistema de enfermagem, a pessoa era levada em sua carreira a um papel social de internado e aprendia ao longo de sua permanência a se adaptar, a orientar-se de forma benéfica no referido sistema.

Para Stebbins, a carreira está presente em todos os “[...] papéis [sociais] complexos incluindo especialmente os do trabalho, lazer, desvio [social], política, religião e relações interpessoais, substanciais" (Stebbins, 2008, p. 11) e no lazer sério representa: 
'This is The End, My Beautiful Friend!'

[...] um percurso ou transição típicos de um amador, praticante de hobby ou voluntário, que leva a pessoa através de e para um papel social de lazer e possivelmente através de e para um papel social de trabalho. A essência de qualquer carreira, seja no trabalho, lazer, ou em outro lugar, encontra-se na continuidade temporal das atividades associadas a ela (Stebbins, 2008, p. 19, tradução autoral).

No lazer sério, a pessoa é levada a um papel social de lazer que se expressa na "[...] aquisição e expressão de uma combinação de habilidades, conhecimento e experiência específicos" (Stebbins, 2008, p. 5). Dessa forma, entendemos que os corredores são educados a adquirir e expressar as "habilidades, conhecimento e experiência" que os permite fazer parte do mundo da corrida de rua e, especialmente, do grupo de corrida que fazem parte.

A resistência e o ritmo foram revelados como as habilidades físicas mais importantes a serem aprendidas dentro do grupo e notamos como essas se relacionavam com o conhecimento e a experiência dos corredores, especialmente dentro das corridas de rua e com outras habilidades em diferentes dimensões (relacionais, por exemplo). O relato de um corredor com 54 anos é elucidativo sobre a resistência e a questão das relações educacionais existentes dentro do grupo na prática do lazer sério:

Você tem um grupo de pessoas praticando esportes, correndo com chuva, correndo com vento, correndo com frio. Então, ele não se importa, ele não se entrega fácil [o corredor]. Fica uma pessoa mais resistente. Eu acho que essa é a grande lição que a corrida nos dá (Corredor, 54 anos)

A resistência, que representa uma capacidade de aguentar, foi a principal habilidade identificada. Nas conversas com os entrevistados, se referia à capacidade de permanecer correndo durante uma distância determinada. A proeminência dessa habilidade faz também sentido na literatura científica, especialmente relacionada à fisiologia. No grupo, a resistência aparecia como característica autodirecionada como nos casos do eu sou resistente e eu aguento o que os outros não aguentam, na comparação entre colegas eu sou mais resistente que fulano e também em negociação. Sobre essa última, por exemplo, temos uma conversa entre um corredor da equipe e um associado no momento final do treino:

E - E o que tu fez hoje, fez tiros ou só rodou?

A - Rodei. Fiz 30 km. Hoje era dia de tiros, mas fiz a rodagem hoje porque não consegui fazer no domingo.

$\mathrm{E}$ - Bah, pra mim é muito isso.

A - É, e hoje ainda tinha uns 12 tiros de mil [metros].

O que chama a atenção é que, nessa conversa, se evidencia um jogo em que o associado (A) mostra que é capaz de rodar (percorrer uma longa distância em ritmo moderado a rápido) uma quilometragem considerada alta por seu parceiro de corrida (E), o que o faz repensar sobre o só que usou na primeira frase, comparando os tiros (distâncias curtas feitas com alta intensidade de corrida, os intervalados) com a rodagem (derivada do rodar) e posicionar-se de outra forma ao dizer que é muito 
para ele. Obviamente, não quer dizer que o corredor, ao dizer que era muito para ele, estava mesmo convencido de que era assim. A segunda habilidade bastante representativa no grupo de corredores é o ritmo. $\mathrm{O}$ ritmo para os corredores se expressa no tempo determinado em que eles devem fazer os tiros ou passar os quilômetros. Uma das explicações para essa valorização do ritmo está no fato de que ele é um fator determinante no sucesso ou fracasso do corredor na prova, do ponto de vista da possibilidade de alcançar sua melhor performance. Se sair muito fraco, o sujeito corre o risco de não fazer seu melhor. Se sair muito forte, corre o risco de cansar-se demais e até abandonar a prova antes do final. A habilidade de ritmo se refere à capacidade de correr na velocidade determinada. Um dos corredores que participavam de provas de maratona se destacava entre os outros por sua capacidade de manter o ritmo. Era um senhor com pouco mais de 50 anos e um de seus colegas de treino, com 35 anos, afirmava:

Podes seguir o fulano que ele vai certinho. Pergunta para ele o ritmo, que ele vai passar cada mil [metros], porque se ele te falar 4min30s é $4 \mathrm{~min} 30 \mathrm{~s}$, se te falar tanto, é tanto. Pode seguir.

\section{A Carreira Entre os Corredores}

Estou voltando é uma expressão que está sempre presente e nos acompanha há anos em nossas observações e análises. Essa expressão surge frequentemente como resposta a perguntas rotineiras entre os corredores, sobretudo, quando dirigida a aqueles que estavam afastados do grupo ou fora das competições por um período de tempo. Por vezes, corredores que recebem o estou voltando como resposta de um colega, prontamente reagem com algum tipo de provocação, em tom de brincadeira: Mas tu estás sempre voltando! Esse tipo de caso revela que em muitas vezes os corredores respondem que estão voltando como uma forma de lidar com uma espécie de obrigação moral que têm de manterem-se em seus papéis ou permanecerem no seu lugar. Isso é o que Stebbins (2008) chamou de "mundo social" característico do "lazer sério". Em um trecho de entrevista é possível identificar bem esse tipo de situação:

Pesquisador - E como tu estás?

Entrevistado - Então, voltei. Estou treinando com o grupo agora, né. Eu voltei, entrei agora. Faz um ano agora que eu estou com o pessoal aqui. Só que, assim, eu não estou conseguindo dar sequência no treino, porque é muito trabalho, muito trabalho. E aí está me atrapalhando um pouco.

O estar voltando frequente nas falas entre os corredores, por um lado, reflete o reconhecimento da existência de um lugar específico por parte dos corredores, onde desempenham seus papéis como tais e desejam manter seus vínculos. Por outro lado, expressa uma resposta tida como moralmente adequada, diante dos valores culturais reconhecidos pelo grupo. O entrevistado anterior ainda apresenta uma justificativa para o que julga ser esperado dele por parte do grupo de corredores - o fato de "não estar conseguindo dar sequência”. Essa forma de posicionamento se aproxima do descrito por Goffman (1974, p. 127),

Educação \& Realidade, Porto Alegre, v. 42, n. 1, p. 215-236, jan./mar. 2017. 
'This is The End, My Beautiful Friend!'

ao especificar de que formas o paciente, em sua adaptação, aprendia a orientar-se no "sistema da enfermaria" do hospital, aproveitando e beneficiando-se de privilégios - como o de um local mais confortável para dormir, por exemplo. Muitas dessas vantagens eram alcançadas quando eles e comportava de acordo com o que se esperava de um paciente em sua situação, ou seja, sua condição material era "uma expressão de seu nível geral de atuação social” (p. 128). Isso nos faz questionar sobre que benefícios ou outros elementos estão envolvidos nessa "negociação de volta" entre os corredores.

Nesse sentido, de entender o voltando como um elemento altamente significativo no mundo da corrida se confirmou quando um de nós, pesquisadores, estava rodando na estrada e foi surpreendido por um outdoor com o seguinte anúncio: Estamos voltando... e correndo. Tratava-se de uma propaganda de uma marca esportiva que tinha parado de produzir tênis no Brasil e estava voltando ao mercado com duas linhas de frente nas vendas de tênis: tênis especiais para o futebol e tênis especiais para as corridas. Entramos em contato com a empresa responsável e fomos informados dos processos de criação propaganda, que envolveu a identificação de elementos que faziam parte do mundo dos corredores.

Como descrito e indicado, esse elemento de volta faz parte da carreira dos corredores do grupo e marca seus percursos. Essas trajetórias não se apresentavam como lineares, bem pelo contrário. Em nosso estudo, o termo voltando serviu também para nos chamar a atenção para o fato de que muitos dos corredores tiveram interrupções em suas carreiras, alguns se afastaram temporariamente e outros, de forma definitiva (como falaremos mais adiante). De acordo com Stebbins (2008, p. 11), a carreira se delineia no lazer sério a partir de "[...] contingências específicas próprias, pontos de inflexão e estágios de realização ou envolvimento" (Stebbins, 2008, p. 11, tradução autoral), elementos muito próximos dos apresentados por Goffman (1974) e descritos por ele como "[...] contingências ou circunstâncias de carreira”. Tratam-se de circunstâncias que marcam o percurso da pessoa de formas determinantes.

No caso dos corredores entrevistados, as contingências aparecem em suas narrativas desde seu início nas corridas até os momentos atuais. Os corredores apresentaram nas entrevistas circunstâncias que os levaram a correr, mudanças na forma de lidar com as práticas envolvidas nas corridas de rua e motivos para deixar de correr por algum tempo. Sobre seu início nas corridas, o que marcava as narrativas era o fato de terem começado a prática por razões médicas (alto estresse, obesidade e hipertensão) e a evidência de um fenômeno que os corredores chamaram de vírus - "[...] isso aí é um vírus que ataca a gente e depois que tu começa, tu não para mais" (Corredor, 50 anos) - e, com mais frequência, de bichinho - "Porque eu tenho certeza de que, mesmo começando devagar e não gostando no início, no momento em que o bichinho pegar ele [o iniciante], ele vai ficar, vai gostar, e vai sentir a falta depois daquilo, de não fazer, né?!” (Corredor, 54 anos). O bichinho representava 
a causa dada pelos corredores para o fato de, aos poucos, saírem de uma condição inicial na prática da corrida e buscarem por desenvolver-se de forma sistemática na atividade.

Assim, é possível identificar as razões que os levaram a correr de forma sistemática - uma forma de levar a corrida a sério, reconhecidamente diferenciada pelos corredores em suas falas. No caso de um dos corredores, na época com 54 anos:

Pesquisador: - E tu começaste por tua conta mesmo?

Corredor: Por conta mesmo, que nem abobado. Ia ali dava umas voltas, né, cansava, via os outros. Aí, depois com dois anos, eu comecei a gostar também, sempre por conta. Mas aí comecei a correr mais.

O gosto pelo progresso na prática e, consequentemente, pela corrida, dentre outros motivos, como o prazer provocado pelo desafio e pela competição, é mais um fator, que leva à mudança na forma de encarar a atividade, em princípio com pouca influência na alteração da rotina e depois considerada viciante. A relevância dessas razões é comprovada por meio dos dados obtidos nas entrevistas e nas observações, sendo reconhecida pelos próprios corredores.

Nas formulações de Stebbins (2012) sobre a carreira estão incluídos cinco possíveis estágios: "iniciação, desenvolvimento, estabelecimento, manutenção e declínio” (Stebbins, 2012, p. 82, tradução autoral). O primeiro estágio da carreira, a iniciação, representa a etapa que dura o tempo necessário para que a atividade se estabeleça minimamente. $\mathrm{O}$ estágio do desenvolvimento se inicia com o interesse em realizar a atividade de forma mais ou menos rotineira e sistemática.

Dessa forma, tanto a necessidade de algo para dar conta das necessidades relacionadas à saúde dos sujeitos (circunstâncias) quanto à modificação na forma de perceberem e lidarem com a prática da corrida (comportamentos), constituem-se nas principais contingências experimentadas pelos corredores na fase inicial de suas carreiras. E, assim, configuram-se as condições para o que seria a realização do primeiro estágio da carreira dos corredores e o início do desenvolvimento, como a fase em que os participantes avançam para além da necessidade de aprender as habilidades e conhecimentos básicos requeridos para a realização das atividades de "lazer sério" (Stebbins, 2012, p. 82).

O estágio de manutenção da carreira representa o pleno vigor de uma prática e, nele, os participantes são capazes de desfrutar o máximo da atividade (Stebbins, 2012). Ao refletir sobre esse estágio que antecede o último, o declínio, nos questionamos sobre como essa etapa pode ser prolongada. As diferentes formas de lidar com a carreira, especialmente nesse penúltimo estágio, fazem com que a fase final seja diferente do padrão linear aparente e esperado na proposta apresentada por Stebbins (2012). Assim, o último estágio, o de declínio transforma-se, em nossas análises, no que se abre como possiblidade de carreira aos sujeitos, diferente das expectativas negativas geradas sobre ele - através de variadas estratégias de envelhecimento. 
'This is The End, My Beautiful Friend!'

\section{O Final da Carreira}

Como mencionado anteriormente, percebemos entre os corredores um esforço no sentido de manterem-se vinculados ao mundo da corrida, permanecendo em seus papéis e, portanto, mantendo suas carreiras. Consideramos relevante que o estudo das carreiras dos corredores do grupo seja associado com as formulações proposta por Baltes e Baltes (1990) sobre o envelhecimento. Embora a carreira implique uma realidade complexa e multidimensional, grande parte da literatura considera mais os seus aspectos objetivos, dando prioridade ao progresso observável em uma ocupação ou organização, e pouca atenção às visões pessoais que se amarram a linhas particulares de ação (Collin; Young, 1986). Em outras palavras, o foco nas carreiras objetivas ou séries de ajustamentos padrão dos indivíduos a redes de instituições e organizações tem ofuscado as carreiras subjetivas ou reconhecimento e interpretação de eventos passados e futuros ligados a cursos sociais específicos da vida dos atores (Stebbins, 1970). Essa mudança no olhar pode estabelecer novas fontes de conhecimento a respeito do envelhecimento.

Com a participação no grupo de corrida, muitas das estratégias utilizadas pelos corredores mais velhos, relacionadas à manutenção de suas carreiras, foram notadas. Essas estratégias delineavam suas carreiras como respostas às contingências específicas, e foram categorizadas. Um conjunto de seis caracterizações de possibilidades de delineamento das carreiras que nos ajudaram a entender esse processo no grupo de corredores. Destas, quatro categorias estão mais voltadas a aspectos sociais de mudanças, incluindo a mudança de carreira entre os corredores, e duas categorias estão situadas nas relações comunicativas entre os corredores, mais centradas em aspectos emocionais ou psicológicos, revelando-se como estratégias para lidar com a carreira e o envelhecimento. As quatro categorias sociais foram:

\section{Mudança de papel, porém permanecendo no mundo das corridas}

Observamos casos diferentes em que corredores, por razões que incluíam seu declínio físico e envelhecimento, mudaram suas atuações. Um dos sujeitos que acompanhamos deixou de participar das corridas, porém permaneceu como uma espécie de gerente, chamado de chefe de equipe. Esse não era seu cargo oficial, mas representava o papel que ele mesmo havia construído a partir de suas relações dentro do grupo. O sujeito organizava a participação de uma equipe, que ele mesmo selecionava, entre seus amigos e conhecidos (considerando suas performances e outros quesitos), para participar de pelo menos duas provas de revezamento que ocorriam durante o ano, a Travessia Torres-Tramandaí (TTT) e a Volta à Ilha, em Santa Catarina.

Esse tipo de característica mudança de papel no desenvolvimento da carreira dos corredores pode ser observado na interessante crônica de Dederich (2009, p. 82). Com o sugestivo título "Relargada", a crôni- 
ca foi publicada em uma revista voltada ao público específico de corredores. No texto, Dederich (2009) conta a história de um corredor que tinha 81 anos e era conhecido como Lata Velha. Ele participava de um grupo regularmente, mas acabou sumindo das atividades. Os colegas tentavam entrar em contato com o veterano por telefone e nunca o encontravam, até que um dia conseguiram falar com ele. Fato é que o corredor tinha sido proibido de continuar nas atividades pelo seu médico, que diagnosticou uma osteoporose crônica. A esposa, percebendo que o marido não iria acatar as ordens, decidiu impedi-lo de continuar a participar dos encontros do grupo. Isso gerou uma discussão com a participação de todos os envolvidos, da esposa, do Lata Velha e do grupo. O final da discussão foi descrito pelo autor assim:

\begin{abstract}
Ao ver seu próprio exército trocar de lado e capitular, Lata pediu a palavra e se rendeu aos cuidados da esposa. Foi quando, vinda lá do fundo, uma voz tímida se fez ouvir. Que parasse de correr, já que sua saúde assim o exigia, mas que não abandonasse as corridas. Havia outras coisas que ele podia fazer sem se prejudicar. Usar sua experiência para ajudar na organização das provas, planejar as viagens de competição ou cuidar da tesouraria da equipe eram algumas sugestões (Dederich, 2009, p. 82).
\end{abstract}

Assim, o corredor Lata Velha se tornou assistente do treinador, mantendo-se ainda envolvido com o grupo. Essa é uma das alternativas que se apresenta aos corredores nas fases finais de suas carreiras.

No mesmo sentido, um estudo de Lewis et al. (2013) sobre a hierarquia entre os praticantes de corrida de motos na Austrália mostrou as possibilidades que se apresentavam aos pilotos em "fim de carreira". O último estágio dos pilotos de moto foi “[...] caracterizado pelo aumento da idade, lesões cumulativas e diminuição de habilidades físicas” (Lewis et al., 2013, p. 189). No caso, a idade foi identificada como uma barreira que restringia o movimento de avanço na carreira, especialmente pela dificuldade em conseguir patrocínio. Entretanto, alguns continuavam no esporte como forma de manter seus vínculos, encontrando outros pilotos, familiares e amigos jovens e velhos, além de ajudar aos mais jovens, atuando como seus mentores.

\title{
2 Mudança na intensidade de envolvimento, mantendo elementos de sentido elou dando prioridade a outros compromissos
}

Em nosso estudo, observamos a variação da intensidade de envolvimento entre os corredores, por diversas razões. Uma delas estava relacionada às novas configurações das provas, outra a questões profissionais, como nos escreveu, por e-mail, um dos corredores do grupo, com 50 anos:

\section{Assunto: notícias}

Boa tarde,

Não tenho participado de provas (está muito caro participar de corridas). Estou rodando 45 min, 5 vezes por semana (para manutenção e saúde). 
'This is The End, My Beautiful Friend!'

Mas, quero voltar a correr.

Estou trabalhando e fazendo cursos voltados para a área de trabalho.

Boa sorte em teu trabalho de pesquisas e muito sucesso.

Esteja à vontade em escrever ao meu respeito.

Abração

Pedimos esclarecimento sobre a participação no grupo e o corredor afirmou: "Só estou rodando. Às vezes, faço o longão [longa distância] de domingo com o grupo". A dificuldade encontrada pelo corredor em sua participação nas provas se aproxima do que McQuarrie e Jackson (2002) conceituaram como "condições limitantes". "Uma condição limitante pode ser definida como qualquer barreira que restrinja um indivíduo de realizar uma ação desejada" (McQuarrie; Jackson, 2002, p. 38, tradução nossa). No primeiro estudo, McQuarrie e Jackson (1996) analisaram a "negociação das condições limitantes" na participação no "lazer sério" de praticantes de patinação no gelo. O termo "negociação das condições limitantes" se referia na literatura relacionada às formas como os sujeitos "lidam com obstáculos ou barreiras" na participação do lazer (McQuarrie; Jackson, 1996, p. 461, tradução autoral).

Para McQuarrie e Jackson (1996), o lazer sério contempla a existência de "condições limitantes" no lazer e os posicionamentos dos sujeitos de forma que os permite lidar com essas condições a partir da adoção de diferentes estratégias. Uma das proposições que se destacam no artigo de McQuarrie e Jackson (1996) consiste na consideração de que "a necessidade de perseverança" e o "esforço pessoal significativo" presentes na teoria de Stebbins (2008, p. 11) poderiam ser reinterpretados por "negociação das condições limitantes".

Ainda McQuarrie e Jackson (1996) entendem que as "[...] condições limitantes estruturais”, que modificam a participação no lazer, e as "condições limitantes antecedentes" - elas afetam as preferências de lazer e podem ser intrapessoais ou interpessoais - ocorreriam de forma simultânea (McQuarrie; Jackson, 1996, p. 462-463, tradução autoral). Além disso, McQuarrie e Jackson (1996) apresentam formulações a respeito das "negociações de condições limitantes", identificando-as dentro de "cinco estágios progressivos da carreira de lazer" - (1) "tornando-se um potencial participante", (2) "iniciando no esporte”, (3) "desenvolvimento", (4) "estabelecimento", (5) "declínio" ou "afastamento” (McQuarrie; Jackson, 1996, p. 467-474, tradução autoral).

Em outro estudo, McQuarrie e Jackson (2002) revisaram análises no contexto do "lazer sério" e das "condições limitantes", propondo-se a identificar estratégias de negociação na "carreira do trabalho" que se assemelhavam às encontradas na "carreira de lazer". McQuarrie e Jackson (2002) traçaram paralelos entre as duas e discutiram três proposições que servem para pensar sobre o tema: (1) "em todos os estágios de uma carreira de trabalho, as condições limitantes não são necessariamente obstáculos intransponíveis, mas podem ser negociadas entre os participantes"; (2) "respostas às condições limitantes encontradas não são necessariamente passivas"; e, (3) "condições limitantes podem causar a transição na carreira, tanto visível quanto invisível” (McQuarrie; Jackson, 2002, p. 47-48, tradução autoral). 
Podemos estabelecer essa mesma relação de mudanças de envolvimento vinculada à manutenção de uma carreira no estudo de Vianna e Eckert (2011). Um ritual tradicional realizado por um grupo de remadores veteranos é analisado em uma perspectiva antropológica. Os veteranos, com idades entre 50 e 90 anos, remavam todos os domingos até uma ilha e ali realizavam o café da manhã. O estudo ilustra como praticantes de uma modalidade esportiva mudam seu envolvimento, mantendo elementos que dão sentido às suas experiências - no caso a prática do remo e a realização do café que já era costume dos remadores quando mais novos.

Em outro estudo qualitativo, Siegenthaler e O’Dell (2003) investigaram a premissa de que o "lazer sério" ajuda no envelhecimento bemsucedido. Os dados foram coletados no sudeste dos USA durante 1998 e 1999. De acordo com Siegenthaler e O’Dell (2003, p.47), foram selecionados homens e mulheres golfistas, mentalmente alertas, com pelo menos 65 anos, solicitados a participar de uma pré-entrevista e uma entrevista em profundidade. Siegenthaler e O'Dell escolheram o golfe por considerá-lo um esporte bastante popular entre os velhos e que por suas características apresentava potenciais para contribuir com o envelhecimento, além de ser bem adequado como "lazer sério". Os golfistas eram oito homens e 11 mulheres com idades entre 67 e 87 anos (média 77 anos). Suas análises revelaram três tipos de golfistas com graus variados de envolvimento/seriedade em relação ao golfe: "Core devotees", aqueles que tinham o golfe como foco central de suas vidas; "Moderate devotees", voltados para o prazer do golfe e tudo que envolvia; e "Social", com função social primária de encontrar e interagir com amigos (Siegenthaler; O'dell, 2003, p. 48). Essas três categorias, relacionadas ao nível de intensidade de envolvimento nas atividades de "lazer sério", foram adequadas por Stebbins (2008, p. 21; 2012, p. 83), visando manter uma terminologia consistente com a pesquisa, a teoria e a generalidade. Em sua "escala de envolvimento", recebeu os termos: "participant, moderate devotee" e "core devotee" (Stebbins, 2008, p. 21; 2012, p. 83).

De acordo com Siegenthaler e O’Dell (2003), foi possível identificar contribuições específicas do golfe para o envelhecimento bemsucedido nos golfistas do tipo "core devotees". O grau de seriedade no esporte acompanhava o grau de contribuição para o envelhecimento bem-sucedido. Siegenthaler e O'Dell (2003) chegaram a conclusão de que atividades de "lazer sério", particularmente aquelas com exigências físicas e cognitivas, contribuíam para o envelhecimento bem-sucedido.

\section{Mudança de grupo e espaço de prática, abrindo novas possibilidades de identidade}

Foi possível observar que havia um trânsito intergrupos pelos corredores. Isso foi constatado durante as competições e rodagens aos fins de semana. Nas competições, pudemos observar por meio dos uniformes que identificavam os grupos as migrações dos corredores. Dentro do grupo, esse movimento foi considerado relativamente pequeno, levando-se em conta o grande número de integrantes. Para essas consi- 
'This is The End, My Beautiful Friend!'

derações, as conversas com treinadores e corredores nos ajudaram bastante. Ao sentirmos falta de algum corredor, perguntávamos sobre ele a alguém que tinha mais proximidade e logo conseguíamos informações.

Em observações de campo fora do grupo, identificamos sentidos que as mudanças de grupo tinham para parte dos corredores que conseguimos acompanhar. Primeiro, a mudança oferecia possibilidades reconhecidas pelos outros corredores. Em um dos casos, por exemplo, o corredor era tido como mediano, ou melhor, seu desempenho na corrida não era considerado algo extraordinário, pois havia um número relativamente grande de integrantes em geral e em sua categoria que atingiam os mesmos resultados. O corredor migrou para outro grupo, no qual seu desempenho estava acima da média, recebendo maior reconhecimento. Dessa forma, a carreira se delineava a partir da mudança de grupo, mantendo em sua base a performance, como expressão das habilidades, conhecimento e experiência. Essa atuação se relativizava de acordo com o espaço, relacionada assim com reconhecimento social dado pelos outros participantes do etos (mundo da corrida).

\section{Alternância em movimentos de ida e vinda entre a carreira da corrida e outras carreiras, mudando de carreira e, interrompendo a da corrida, total, periódica ou parcialmente}

Como participantes do mundo da corrida, nós mesmos pesquisadores-corredores experimentamos alternâncias entre afastamentos e voltas para a prática da atividade, seja por questões de saúde, seja por exigências profissionais ou por opções por outros campos de ação. Essa movimentação também merece análise neste artigo.

Hastings, Kurth e Meyers (1989) investigaram as carreiras de nadadores. Os autores iniciam seu artigo considerando limitados os modelos de carreira, por sua aplicabilidade restrita. Um dos aspectos que destacaram é o fato desses modelos não incluírem as pausas e interrupções possíveis. Essas descontinuidades na carreira (Hastings, Kurth; Meyers, 1989, p. 278, tradução nossa) poderiam se dar pela prioridade orientada a outra carreira, de forma permanente ou temporária - a essa última forma, Hastings e Meyers (1989, p. 278, tradução autoral), nomearam de "dormente", em vez de "terminal", como tipicamente era representada.

Para Hastings, Kurth e Meyers (1989), a reentrada na carreira ou reassunção dela ocorria "[...] quando as demandas de outras carreiras diminuem, ou as prioridades se deslocam, ou os recursos mudam" (Hastings; Kurth; Meyers, 1989, p. 279, tradução autoral). Ainda, segundo os autores, a inclusão de fases de "dormência" e "reentrada" facilitavam a análise do movimento entre as carreiras, bem como a mudança de padrões de envolvimento na carreira esportiva durante o curso de vida (Hastings; Kurth; Meyers, 1989, p. 279, tradução nossa).

Embora a abordagem sobre o tema analisado por Hastings, Kurth e Meyers (1989) não esteja tão próxima do estudo aqui proposto - o curso de vida é tomado pelos autores como uma categoria representada de modo etário, por exemplo -, os aspectos destacados acima são conside- 
rados importantes por enfocarem elementos que enriquecem a análise da carreira. As possíveis alternâncias, interrupções e retomadas dentro dos estágios de envolvimento no lazer sério e de suas fases de desenvolvimento se tornam elementos-chave quando consideramos o estudo ancorado em uma perspectiva que compreende o desenvolvimento ao longo da vida dos sujeitos.

Robert Stebbins (2014) identificou três principais alternativas que podem levar um indivíduo a abandonar uma atividade de lazer em particular. A primeira é a decisão consciente de encerrar a atividade. A segunda é quando o praticante é forçado a abandoná-la por circunstancias externas. E a última é quando ele vai se afastando da atividade perdendo seu interesse aos poucos.

Além das quatro formas de lidar com os desafios do final da carreira, existem dois outros aspectos que chamaram nossa atenção. Não são formas específicas de encaminhar a trilha escolhida, mas estratégias que corredores utilizam para lidar com aspectos e suas carreiras e envelhecimento:

\section{Considerar sua performance por meio do outro com a mesma idade}

Um dos delineamentos dados pelos corredores às suas próprias carreiras estava ligado à estratégia de utilizar em suas referências parâmetros que faziam parte da avaliação de desempenho considerada oficial. Um dos exemplos mais observados não estava restrito aos velhos, porém se apresentava com maior ênfase, foi a utilização da comparação dentro da categoria etária. Em outras palavras, os corredores se utilizavam da proposta de categorias etárias instituída oficialmente para valorizar suas realizações, relativizando a questão da performance na corrida.

\section{Lidar de forma irônica, ou "na brincadeira" com aspectos que se apresentam como de tensão ou de difícil resolução}

Em um mundo rodeado de questões sérias, com uma forte necessidade de esforços para superar desafios e de perseverar com os altos e baixos nos resultados das corridas, a brincadeira não parece um elemento adequado ao cenário. Porém, por mais estranho que possa parecer, é brincando, debochando e ironizando que os corredores expressavam suas formas de lidar com questões muito sérias de suas vidas.

\section{Considerações Finais}

Em nossa análise, identificamos processos distintos e interdependentes que contextualizam a inserção social do grupo de corredores, como: 1) a transição de perfil do participante das corridas de rua; 2) o surgimento de novos modelos de corridas de rua; e 3) o surgimento dos grupos de corrida. Mesmo com o passar dos últimos anos e com a aceleração e estabelecimento de processos que vinham ocorrendo em torno do fenômeno esportivo e mesmo do envelhecimento no contexto das corridas, os dados construídos a partir do estudo nos parecem bastante relevantes na atualidade. Essa importância se apresenta principalmente na identifica- 
'This is The End, My Beautiful Friend!'

ção de elementos que, em nossa análise, estão nas bases desses mesmos processos e nos ajudam a entender um pouco mais sobre as trajetórias dos corredores de rua em um contexto mais amplo que o do grupo.

Como uma forma de reforçar nossa argumentação, acrescentamos dados que obtivemos não por participar especificamente do grupo de corrida, mas por estarmos inseridos em um universo maior de corredores, inscritos em provas de longa distância - e, por isso, tendo contato com outros participantes que nem sempre se consideravam ou eram considerados corredores - treinando nas ruas da cidade e, dentre outras coisas, nos tornado alvos de ações de marketing de produtos, para citar alguns exemplos.

Consideramos que os dados que obtivemos indicavam uma relativa generalização da presença de elementos que encontramos no grupo, para níveis maiores do que este. Em outras palavras, muitos elementos que poderiam parecer peculiares do grupo de corrida acabaram sendo observados em níveis mais amplos dentro do contexto das corridas de rua. De forma sintética, conseguimos identificar no grupo quatro possibilidades de delineamento de suas carreiras, especialmente em suas fases finais: 1) mudança de papel; 2) mudança de intensidade no envolvimento; 3) mudança de grupo; 4) alternância em movimentos de ida e vinda. E duas estratégias de enfrentamento dos desafios relacionados à carreira $\mathrm{e}$ envelhecimento no etos: 1) considerar seu desempenho por meio do outro; e, 2) lidar de forma irônica com aspectos de tensão ou difícil resolução.

O último estágio descrito, o declínio, não é necessariamente experimentado por todos os participantes, mas os que o vivenciam, em geral, têm como causa a deterioração de habilidades mentais ou físicas. O último estágio nos leva também a refletir, para além o grupo de corredores, sobre o que a carreira de lazer sério poderia representar para os sujeitos na velhice. A carreira poderia oferecer uma possibilidade de continuidade no que diz respeito a manter, por exemplo, aposentados em atividades que fazem sentido para eles e que lhes proporcionam valores vinculados a uma identidade que não desejam perder - especialmente valores ligados ao trabalho. Ainda, a carreira poderia representar a possibilidade de o sujeito se associar a uma imagem que o afasta da velhice comum e o torna diferente (um indicativo que surgiu nas análises do grupo), permitindo-lhe transitar em espaços que eram anteriormente restritos a poucos de idade avançada e a ocupar lugares diferentes dos tradicionalmente relacionados à velhice (asilos e lares, grupos de convivência).

Olhando mais especificamente para o que poderia ser o mundo social específico do lazer sério, a carreira poderia representar alternativas de manutenção do vínculo com as práticas de lazer, através da atuação em diferentes papéis, como quando o sujeito deixa a atividade principal e, portanto, não é mais coadjuvante (corredor, no caso) e passa a assumir um papel secundário de auxiliar, mentor, ou algo nesse sentido.

Recebido em 14 de novembro de 2014 Aprovado em 01 de março de 2016 


\section{Notas}

1 Alusão à famosa música da banda The Doors, escrita por Jim Morrison, lançada em 1967.

2 Os dados apresentados são oriundos de análises feitas sobre as participações em corridas que compunham o "Circuito de Corridas CORPA", em provas ocorridas durante os anos de 2005 a 2009. Dados referentes aos eventos realizados em Porto Alegre foram obtidos e analisados a partir de informações oferecidas no site do Clube de Corredores de Porto Alegre (CORPA), principal entidade responsável pela organização das corridas de rua no RS. As "faixas etárias" são comumente utilizadas, tanto pelo CORPA quanto por outros organizadores de corridas de rua, visando separar corredores em categorias graduais de cinco em cinco anos de idade. Mais informações ver <http://www.corpa.esp.br>. Acesso em: 01 nov. 2014.

\section{Referências}

ADLER, Patricia; ADLER, Peter. Observational techniques. In: DENZIN, Norman; LINCOLN, Yvonna (Org.). Handbook of Qualitative Research. London: Sage, 1994. P. 377-392

BALTES, Paul; BALTES, Margret. Psychological Perspectives on Successful Aging: The model of selective optimization with compensation. Successful Aging: Perspectives from the behavioral sciences. New York: Cambridge University, v. 1, p. 1-34, 1990.

BECKER, Howard Saul. The Career of the Chicago Public Schoolteacher. American Journal of Sociology: The Sociological Study of Work, v. 57, n. 5, p. 470-477, 1952.

COLLIN, Alan; YOUNG, Richard. New Directions for Theories of Career. Human Relations, v. 39, n. 9, p. 837-853, 1986.

CRESWELL, John; PLANO CLARK, Vicki. Designing and Conducting Mixed Methods Research. Califórnia: Sage, 2011.

DEDERICH, Márcio. Espírito Corredor. Relargada. Contra-Relógio, São Paulo, Ano 17, n. 184, p. 82, jan. 2009.

GLASER, Barney; STRAUSS, Anselm. The Discover of Grounded Theory: strategies for qualitative research. Beverly Hills, CA: Sage, 1967.

GOFFMAN, Ervin. Manicômios, Prisões e Conventos. São Paulo: Perspectiva, 1974. HASTINGS, Donald; KURTH, Suzanne; MEYER, Judy. Competitive Swimming Careers Through the Life Course. Sociology of Sport Journal, Minnesota, v. 6, n. 3, 1989.

LEWIS, Jan; PATTERSON, Ian; PEGG, Shane. The Serious Leisure Career Hierarchy of Australian Motorcycle Road Racers. World Leisure Journal, v. 55, n. 2, p. 179-192, 2013.

MCQUARRIE, Fiona; JACKSON, Edgar. Connections Between Negotiation of Leisure Constraints and Serious Leisure: an explanatory study of adult amateur ice skaters. Society and Leisure, v. 19, p. 459-483, 1996.

MCQUARRIE, Fiona; JACKSON, Edgar. Transitions in Leisure Careers and Their Parallels in Work Careers: The effect of constraints on choice and action. Journal of Career Development, v. 29, n. 1, p. 37-53, 2002.

OLIVEIRA, Saulo Neves; DOLL, Johannes. O Serious Leisure de Robert A. Stebbins. Licere, Belo Horizonte, v. 17, n. 1, mar. 2014.

PATTON, Michael Quinn. Qualitative Evaluation \& Research Methods. 3 Ed. Thousand Oaks, CA: Sage, 2002. 
SALGADO, José Vítor Vieira; CHACON-MIKAHIL, Mara Patrícia Traina. Corrida de Rua: análise do crescimento do número de provas e de praticantes. Conexões, São Paulo, v. 4, n. 1. 2006.

SARKIS, Miguel. A Construção do Corredor. São Paulo: Gente, 2009.

SIEGENTHALER, Kim; O'DELL, Irma. Older Golfers: Serious leisure and successful aging. World Leisure Journal, v. 45, n. 1, p. 45-52, 2003.

STEBBINS, Robert. Career: The Subjective Approach. The Sociological Quarterly, v. 11, n. 1, p. 32-49, 1970.

STEBBINS, Robert. Serious leisure: A conceptual statement. Pacific Sociological Review, Califórnia, v. 25, p. 251-272, 1982.

STEBBINS, Robert. Exploratory Research in the Social Sciences. Thousand Oaks, CA: Sage, 2001.

STEBBINS, Robert. Serious Leisure: a perspective for our time. New Jersey: Transaction, 2008.

STEBBINS, Robert. The Idea of Leisure: first principles. New Jersey: Transaction, 2012.

STEBBINS, Robert. Career in Serious Leisure: from dabbler to devotee in search of fulfillment. London: Palgrave McMillan, 2014.

STEBBINS, Robert. Dumazedier, The Serious Leisure Perspective, and Leisure in Brazil. World Leisure Journal, 2016.

STIGGER, Marco Paulo. Lazer, Cultura e Educação: possíveis articulações. In: Revista Brasileira de Ciências do Esporte, Campinas. v. 30, n. 2, p. 73-88, jan. 2009.

UNRUH, David. Characteristics and Types of Participation in Social Worlds. Symbolic Interaction, v. 2, n. 2, p. 115-130, 1979.

UNRUH, David. The nature of social worlds. Pacific Sociological Review. v. 23, n. 03, p. 271-296, 1980.

VIANNA, Luciano von der Goltz; ECKERT, Cornelia. Projetos para Envelhecer: etnografia das formas de sociabilidades e das trajetórias de vida de veteranos do remo. São Paulo: Iluminuras, 2011.

VILLAR, Feliciano. Successful Ageing and Development: the contribution of generativity in older age. Ageing and Society, Champaign, v. 32, n. 7, p. 1087-1105, 2012.

Saulo Neves de Oliveira é professor de Educação Física. Doutor e mestre em Educação pela Faculdade de Educação da Universidade Federal do Rio Grande do Sul (FACEd/UFRGS), na linha de Trabalho, Movimentos Sociais e Educação (TRAMSE). Especialista em mídias na Educação (UAB). Colaborador no Núcleo de Estudos Interdisciplinares do Envelhecimento (NEIE). Pesquisa na temática lazer sério, esportes e envelhecimento.

E-mail: sauloneves@ibest.com.br

Johannes Doll é pedagogo, teólogo, gerontólogo. Possui mestrado em Educação pela Universidade Federal do Rio Grande do Sul/UFRGS e doutorado em Educação pela Universitat Koblenz Landau. Atua como docente da graduação e pós-graduação em Educação na UFRGS. Tem experiência na área de Educação, com ênfase em Educação, atuando principalmente nos seguintes temas: envelhecimento, educação, gerontologia, trabalhadores mais velhos e informática.

E-mail: johannes.doll@ufrgs.br 